\title{
Fracture Test Methods for Plastically Responding COPV Liners
}

\author{
David S, Dawicke ${ }^{1}$ \\ Analytical Services and Materials, Inc, Hampton VA, 23666 \\ and \\ Joseph C. Lewis ${ }^{2}$ \\ Jet Propulsion Laboratory, California Institute of Technology, Pasadena, CA, 91109
}

\begin{abstract}
An experimental procedure for evaluating the validity of using uniaxial tests to provide a conservative bound on the fatigue crack growth rate behavior small cracks in bi-axially loaded Composite Overwrapped Pressure Vessel (COPV) liners is described. The experimental procedure included the use of a laser notch to quickly generate small surface fatigue cracks with the desired size and aspect ratios. An out-of-plane constraint system was designed to allow fully reversed, fully plastic testing of thin sheet uniaxial coupons. Finally, a method was developed to determine to initiate small cracks in the liner of COPVs.
\end{abstract}

\section{Nomenclature}

COPV = composite overwrapped pressure vessel

$L B B=$ leak before break

$M D P=$ maximum design pressure

$a \quad=$ surface crack depth

$c \quad=$ half surface crack length

$\mathrm{R}=\quad$ ratio of minimum cyclic stress to maximum cyclic stress

$\mathrm{S} \quad=$ applied stress

$\mathrm{S}_{0} \quad=$ yield stress

\section{Introduction}

$\mathrm{T}$

HE development of composite overwrapped pressure vessels (COPV) has greatly reduced the mass of aerospace pressure vessels compared to those made of monolithic metals such as titanium, aluminum and nickel-base alloys. ANSI/AIAA S-081A-2006 defines a COPV as "a pressure vessel with a composite shell fully or partially encapsulating a metallic liner" (1). The metallic liner may be either elastically responding or plastically responding depending on the strain in the liner at the proof pressure (1). Plastically responding liners offer the advantages of lower mass and potentially lower manufacturing cost.

Reference 1 requires that two different fracture control conditions be met in the liner and be verified during COPV qualification. These are 1) Damage-Tolerance Life (Safe-Life) and 2) Leak-Before-Burst (LBB). Safe-Life means that the largest crack that can escape detection to $90 \%$ probability with $95 \%$ confidence by a non-destructive examination (NDE) shall not grow to liner fracture or leakage in four service lives. LBB means that if a crack in the liner is growing at the maximum design pressure (MDP) by any growth mechanism, that crack will grow through the liner thickness and leak the pressurizing fluid out without liner fracture occurring. For plastically responding liners, both safe-life and LBB requirements must be verified by test using coupons or COPV specimens.

Before the release of Reference 1, for COPVs containing non-hazardous fluids, a manufacturer was only required to verify safe-life or LBB but not both (2). LBB verification is usually selected by the manufacturer

\footnotetext{
${ }^{1}$ Senior Research Scientist.

${ }^{2}$ Senior Research Scientist.
} 
because a test method is available that costs less than developing a new test method to verify safe-life. The latest revision of the standard, S-081A requires that both safe-life and LBB be verified. In addition, although use of uniaxial coupons is allowed for safe-life verification (1), no data exists that show that the crack growth rates in the uniaxial strain field of the coupon tests are conservative when compared to those in the multiaxial strain fields that exist in a plastically responding COPV liner. Therefore, the NASA Engineering \& Safety Center (NESC) funded a task under the guidance of the NESC Composite Pressure Vessels Working Group to develop test methods for elastic/plastic crack-growth testing for COPV liners (3). This paper describes the activities conducted by the assessment team including: a discussion of the behavior of plastically responding liners, the concepts used to develop test methods for Save-Life and LBB COPV qualification, and the development of a test procedure to evaluate the differences and similarities between crack growth in uniaxial and multiaxial strain fields.

\section{Strain Behavior of Plastically Responding Liners}

The liner undergoes its maximum tensile strain during initial pressurization to the proof pressure. The proof test strain is about 12,500 microstrain or 3.5 times the uniaxial yield strain in a carbon-fiber-overwrapped COPV liner having a 1.5 design burst factor, a 1.25 proof test factor and a thin 6061-T62 liner. The carbon fiber remains elastic during this proof pressurization. When the pressure is reduced to zero the elastic relaxation of the higher modulus carbon fiber drives the liner back beyond its compression yield strain. Subsequent pressurization to the MDP strains the liner in tension to about 10,000 microstrain or 2.8 times its uniaxial yield strain. For a non-strain-hardening alloy such as 6061-T62, this plastic strain cycle is repeated with each pressurization cycle to the MDP or higher pressure. Figure 1 shows these strain hysteresis loops that were generated uniaxially. The loops in Figure 1 simulate the expected behavior of very thin liners in COPVs wrapped with carbon-fiber composite. The loops are unique to each COPV design and for thicker liners the amount of strain beyond the compression yield strain at zero pressure is usually less than that shown in Figure 1 because relative difference between the liner stiffness and the composite thickness is less as the liner thickness increases.

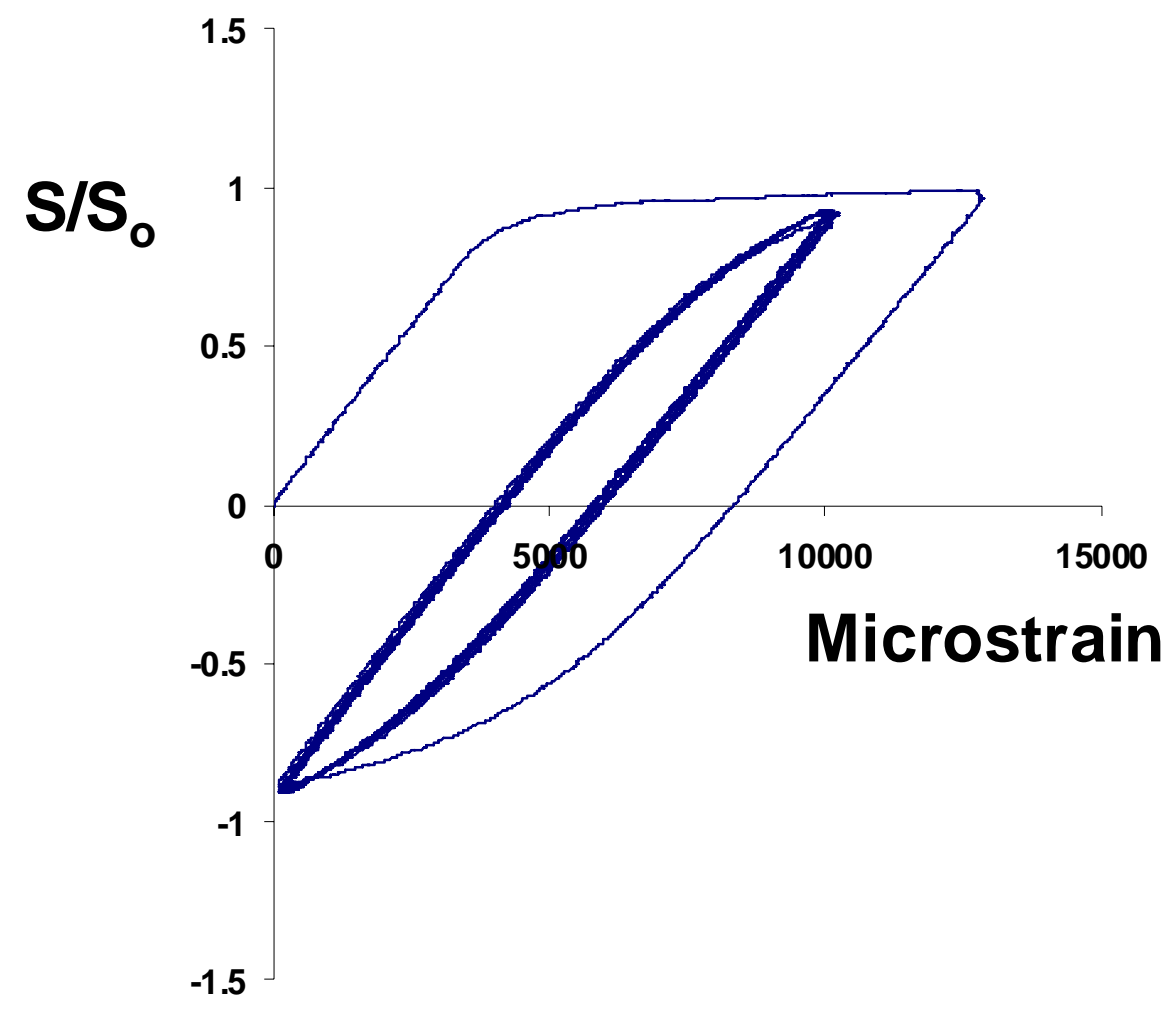

Figure 1 Typical strain hysteresis loop of a COPV with a plastically responding liner. 


\section{Approach to Test Method Development}

The basic approach to developing the test method was to put a fatigue-generated pre-crack into the test specimen that was equal in size and shape to the sensitivity limits of the NDE method to be used to inspect the liner for initial cracks. Both Reference 1 and Reference 2 require that verification be performed for cracks whose length is twice their depth (2:1 cracks) and cracks whose length is ten times their depth (10:1 cracks). Then, the actual strain histogram specified for the liner is applied to the specimen and repeated in sequence four times or a minimum of fifty loops, whichever is greater. At the end of these strain cycles the specimen must not have fractured and the crack must not have broken through the back-face (leakage).

Since COPV mass is linear with liner mass, liner mass is linear with liner thickness and minimum allowable liner thickness is determined by the initial crack size as determined by an NDE process that has been established from a valid probability-of-detection test with sensitivity limits having $90 \%$ probability with $95 \%$ confidence. The certified NDE process capable of detecting the smallest cracks is usually used. For wrought metal, that process is currently Enhanced NSTS Orbiter Special Penetrant Inspection. The certified 90-95 sensitivity limits for this process are a crack that is 0.030 -inch length by 0.015 -inch depth for a semi-circular crack and 0.070 -inch length by 0.007 -inch depth for a long, shallow crack. When this assessment began Enhanced NSTS Orbiter Special Penetrant Inspection had not been certified to $90 \%$ probability and $95 \%$ confidence so NSTS Orbiter Penetration Inspection (4) sensitivity limits of 0.050 -inch length by 0.025 -inch depth (2:1) and 0.125-inch length by 0.0125 -inch depth (10:1) were used. The sensitivity limits of Enhanced NSTS Orbiter Penetrant Inspection were checked on a few specimens to verify similar crack growth behavior.

Since the isotensoid head shape used with cylindrical COPVs has regions of both uniaxial strain and multiaxial strain, the quantitative relationship between crack-growth rates in the two types needs to be determined. Uniaxial testing is preferred if it exhibits equivalent or more severe crack-growth rates because it is quicker and lower cost than testing with COPVs.

\section{Determination of Test Location for Safe Life Verification}

S-081A requires that, for both safe-life and LBB verification, the crack must be positioned in the worst-case location in the liner profile for parent metal, welds, and heat-affected zones (HAZ). "Worst-case" means that the liner is most prone to fracture or leak. An elastic fracture mechanics analysis program such as NASGRO (5) can be used to determine this location. Most COPV designs are axi-symmetric so only one slice through the circumference has to be searched to find this location. For safe-life verification the worst-case location is usually in the thinnest region that is highly strained (stressed).

Only the approach for the parent metal regions will be described herein. This approach must be applied similarly to weld and HAZ regions with NSTS Orbiter Radiographic Inspection (4) sensitivity limits and aspect ratios appropriate for these regions.

A finite-element model (FEM) for the COPV is needed to estimate both elastic and plastic liner strains versus pressure along the liner profile. A profile of liner thickness should be superimposed over the strain profile for each region where either the thickness or strain varies significantly. For example a long constant-thickness cylindrical section would need to be examined at only the center and at the head to cylinder junction. The combination of strain and thickness will determine the fracture behavior of each region.

Using an elastic stress, an elastic fracture mechanics analysis program such as NASGRO should first be used to determine the critical aspect ratio, a/c, for aspect ratios between 0.2 and 0.5 , with the highest stress intensity factor. The crack size of the NASGRO type analysis should be the sensitivity limit of the non-destructive inspection (NDI) with a $90 \%$ probability of detection with $95 \%$ confidence of detection. This critical aspect ratio will vary with thickness so the thinnest liner thickness should be used for this analysis. Figure 2 is an example of the effect of aspect ratio on the applied stress intensity factor for two different thicknesses of 6061-T6 aluminum alloy. This critical initial crack size and aspect ratio should be used to determine the region of the liner that is most prone to fracture. 


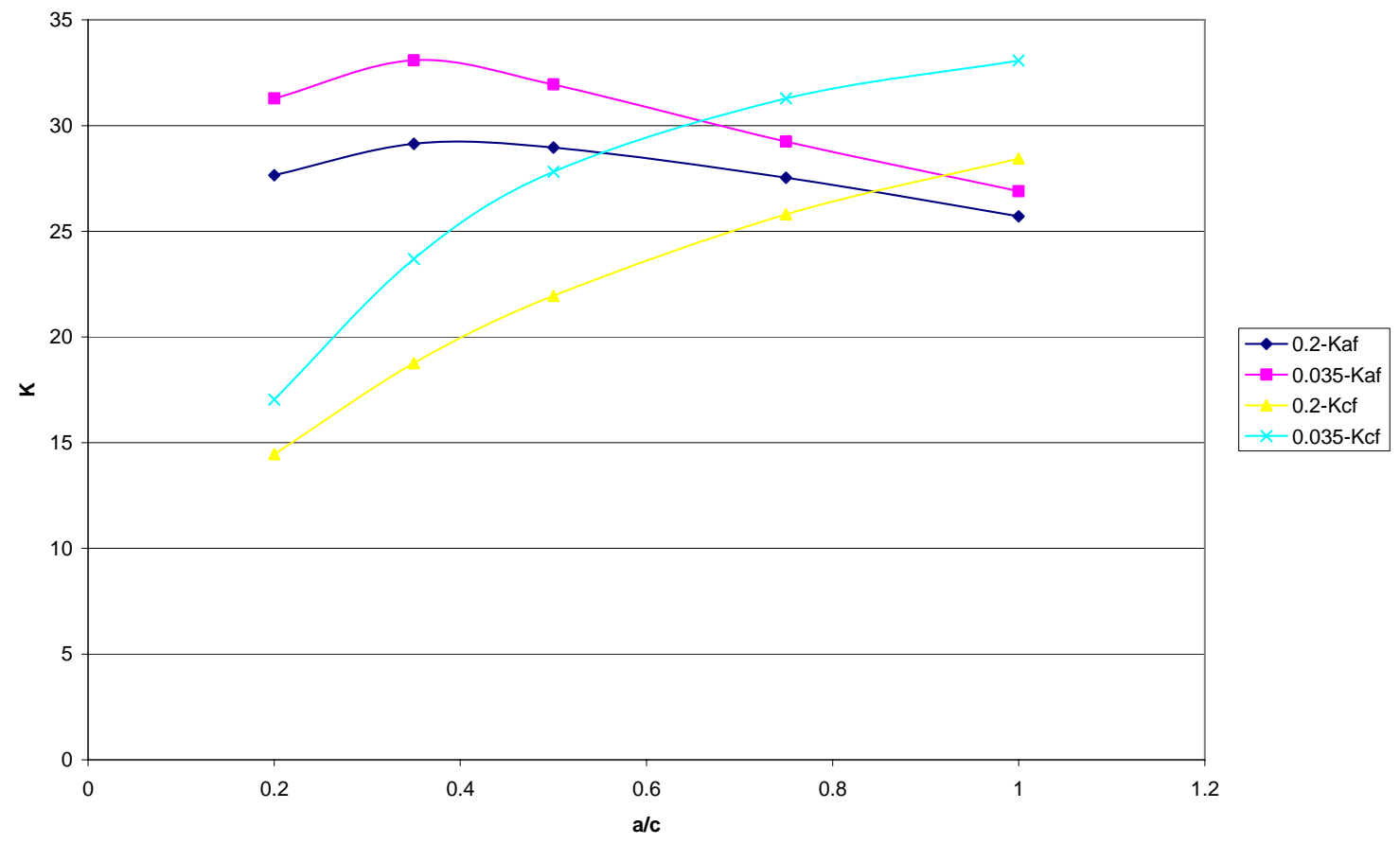

Figure $2 K_{a f}$ and $K_{c f}$ for 0.2 and 0.035 thicknesses of 6061-T62 Aluminum.

Next, a pressure value for which all regions of the liner have elastic stresses should be selected from the strainversus-pressure curve. The elastic stresses at this pressure should be superimposed onto the thickness profile. Using the initial crack size with the critical aspect ratio and the elastic stresses from the liner profile, an elastic fracture mechanics analysis should be done to determine the liner region that results in the highest applied stress intensity factor after the crack has grown during four times the number of cycles in the service life have been applied to the initial crack. This region is where the crack in the COPV liner should be placed to verify that the crack will not grow to fracture in the required number of strain cycles. Only one region can be tested per specimen.

Next, an elastic fracture mechanics analysis should be done for the thinnest liner regions using the elastic stress profile and an initial crack size from the NDI process, having an aspect ratio of 0.5 and applying four times the service-life cycles. A separate test with this initial crack should be performed.

Verification of safe-life requires two separate test specimens, one to demonstrate that the liner will not fracture and one to demonstrate that the liner will not leak.

The worst-case location in the liner profile for verification of LBB can be determined by a similar elastic analysis using NASGRO. Using the previously described elastic stress profile, a through-crack solution should be used to find the location where a crack whose length is ten times the thickness shows the highest applied stress intensity factor. This location will generally be one that has a high combination of thickness and stress. For a COPV specimen the initial crack must be a part-through crack introduced into the liner before wrapping and the test pressurization system must have enough capacity to overcome the leak once the crack grows through the thickness. For coupon testing the crack can be a through-crack whose length is less than ten times the thickness.

\section{Testing}

The characterization of the fatigue crack growth behavior of the metallic liners of composite overwrapped pressure vessels (CPOVs) was examined through uniaxial tests conducted on 6061-T62 Aluminum sheets and biaxial tests conducted on wrapped liners. Uniaxial static tests were conducted on the Aluminum sheet material to determine the elastic modulus, yield, and the post-yield stress-strain behavior. Uniaxial fatigue tests were conducted to determine the fatigue crack growth rate behavior of small surface cracks. Cyclic pressurized tests will be 
conducted on COPVs with Aluminum liners with small surface cracks to determine the fatigue crack growth rate behavior under bi-axial loading. The following Sub-sections provide an overview of each type of test. The subsequent Sections provide additional details on specific aspects of the tests.

\section{A. Uniaxial Static Tests}

Uniaxial static tests were conducted on each lot of material used in the uniaxial fatigue crack growth tests. Standard tensile tests [6] were conducted on 0.5 inch wide by 6 inch long dogbone specimens. Extensometers with a one inch gage length were attached on opposite edges of the specimens. Quasi-static loading was applied at room temperature and load and extensometer measurements were made every second. The engineering stress was obtained from the load measurements and the original specimen dimensions. The engineering strain was obtained by averaging the extensometer measurements.

\section{B. Uniaxal Fatigue Tests}

Uniaxial fatigue crack growth rate tests were conducted on 2-inch wide dogbone specimens with small surface cracks, as shown in Figure 3. The surface cracks were generated by establishing a small defect using a laser notching process. Two types of surface cracks were examined: semi-circular cracks (the ratio of depth to length a/c $=1)$ and long shallow cracks $(\mathrm{a} / \mathrm{c}>0.2)$. The measurement of fatigue crack growth rate $(\mathrm{da} / \mathrm{dN})$ was obtained by

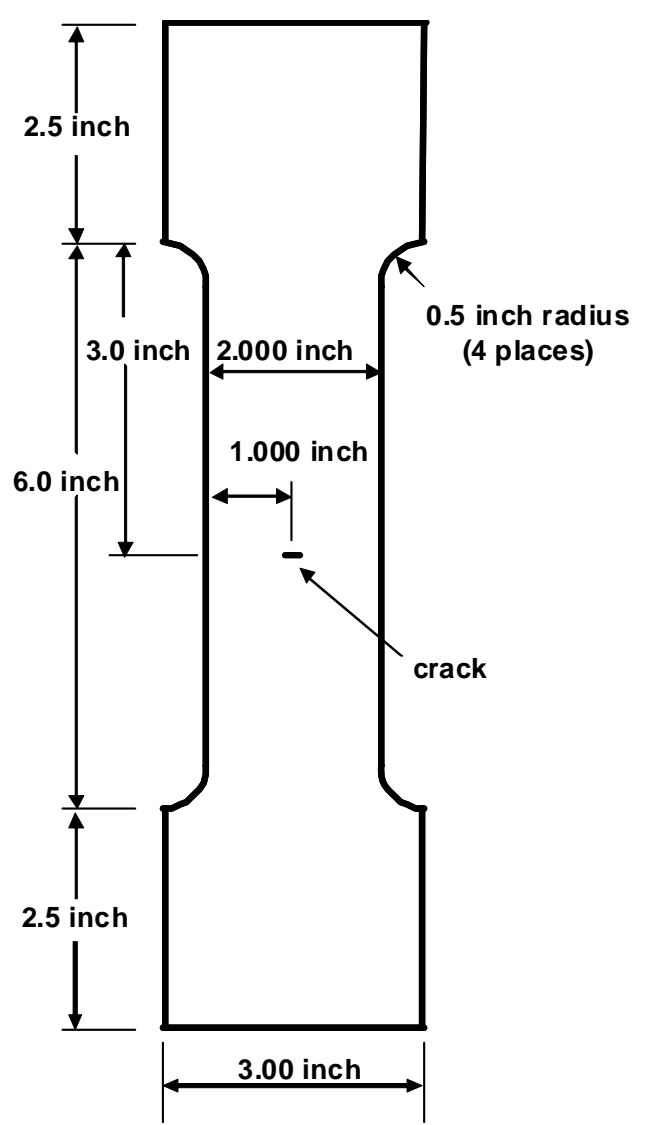

Figure 3 Drawing of dogbone specimen. fractographic examination of the fracture surfaces. The morphology of the fracture surfaces generated by the fatigue precracking, the cyclic fatigue, and the final fracture are sufficiently different to allow direct measurement of the crack extension along the entire surface of the crack.

The uniaxial tests were conducted under fully reversed cyclic strain conditions that simulated the stresses typical of COPV flight usage. Guide plates were used to constrain the out-of-plane displacements from buckling of the thin sheet specimens under compressive loading. The guide plates were designed to allow the specimen to extend 0.05 inches outside of the guide plates. The strain was measured using extensometers that were mounted on the edges of the specimen remaining outside of the guide plates.

\section{Bi-axial Tests}

The bi-axial tests were conducted using cylinders that were 0.09 inches thick, 6.38 inches in diameter and 22 inches long. Small laser notches, identical to that used in the uniaxial tests, were placed in three locations around the Aluminum, unwrapped cylinder. The unwrapped cylinders were precracked under a cyclic pressure range that resulted in crack opening stresses that were identical to the uniaxial cyclic stresses. The cylinders were wrapped with carbon fiber composite after precracking for future testing under pressures that simulate the conditions of typical COPV

flight usage. The cylinders will be cut open after testing and the crack surfaces examined as was done with the uniaxial specimens. 


\section{Crack Initiation and Growth}

Fatigue cracks were initiated in the uniaxial bi-axial specimens by fatigue precracking defects that were created by a laser notching process. The laser notch process creates a small, sharp defect that quickly initiates fatigue cracks when subjected to cyclic loading. A typical cross section of a laser notch is shown in Figure 4 and a typical fracture surface is shown in Figure 5. A region of melted or "recast" material was present at the depth of the laser notch. These sharp, "finger-like" regions appear to further increase the stress concentration of the defect, promoting early fatigue crack initiation. All of the fatigue precracking was performed at a maximum stress equal to $80 \%$ of the yield stress of the material and a stress ratio of $\mathrm{R}=0.1$ and allowed the crack to grow beyond the recast region.

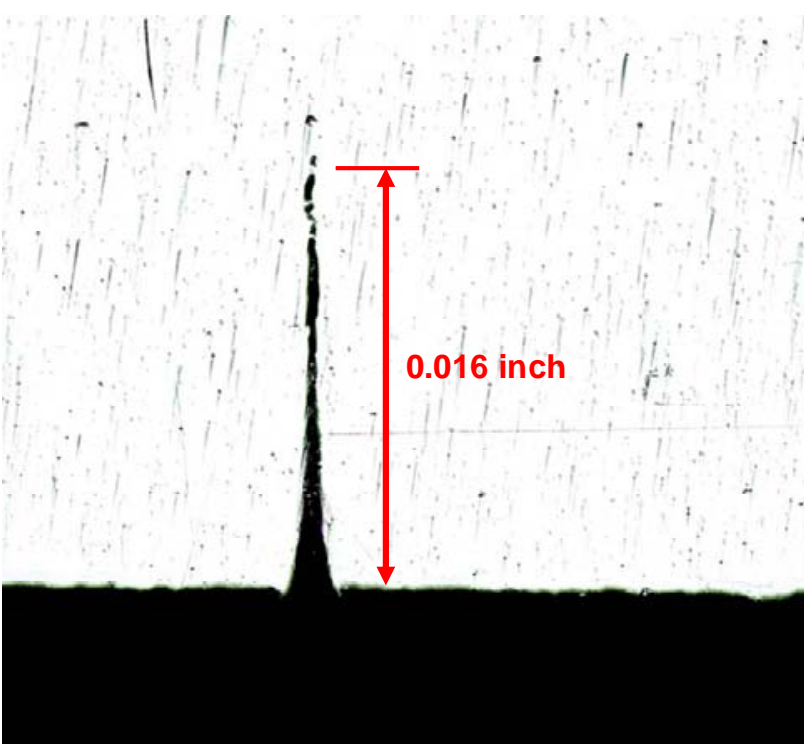

Figure 4 Typical cross section of a laser notch.

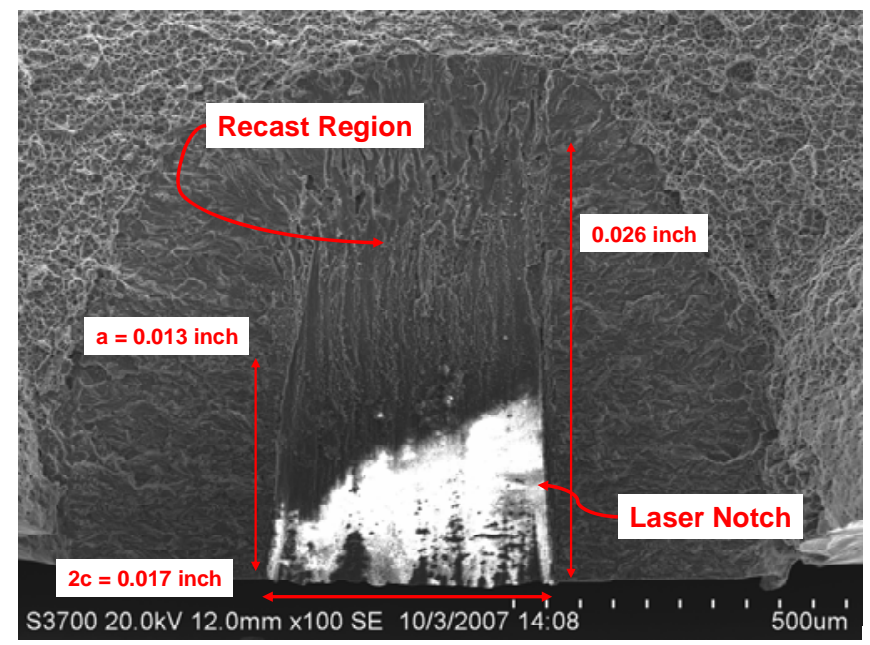

Figure 5 Typical fracture surface view of a laser notch.

The laser notches for the small semi-circular fatigue cracks were on the order of 0.02 inches in surface length (2c) and 0.01 inches in depth (a). The recast region tended to increase the effective depth of the notch, resulting in fatigue cracks with aspect ratios $(\mathrm{a} / \mathrm{c})$ of 1.0 to 1.4 after precracking. The precracking was performed until the surface crack length was $2 \mathrm{c}=0.04$ inches.

The laser notches for the long, shallow fatigue cracks were on the order of $2 \mathrm{c}=0.1$ inches in length and $\mathrm{a}=0.01$ inches in depth. The recast region again, tended to increase the effective depth of the notch, resulting in fatigue cracks with aspect ratios $(\mathrm{a} / \mathrm{c})$ of 0.2 to 0.4 after precracking. The precracking was performed until the evidence of surface crack growth was visible on both sides of the laser notch.

\section{A. Fatigue Crack Marking}

The precracking was performed at a stress level of $80 \%$ of the material yield stress and a stress ratio of $\mathrm{R}=0.1$. The fatigue testing of the uniaxial and bi-axial specimens were conducted at stresses above yield and a fully reversed stress ratio $\mathrm{R}=-1$. The specimens were loaded monotonically to failure after the desired number of fatigue cycles had been achieved. The resulting fracture surface revealed four distinct regions: laser notch, precracking, $\mathrm{R}=$ -1 fatigue, and ductile overload, as illustrated in Figure 6. The crack growth rate was obtained by measuring the difference between the crack front after precracking and the crack front marked by the ductile overload and dividing by the number of applied fatigue cycles. 


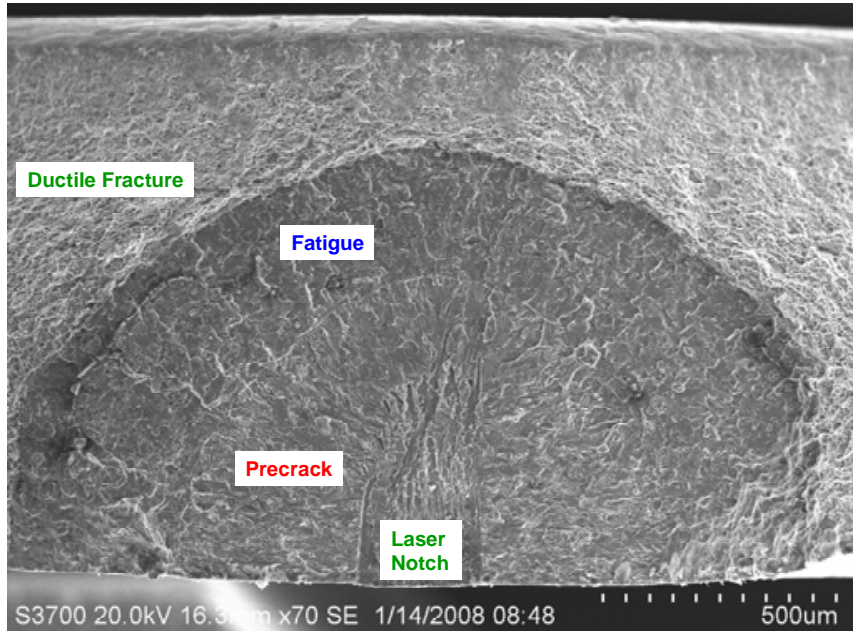

Figure 6 Typical fracture surface.

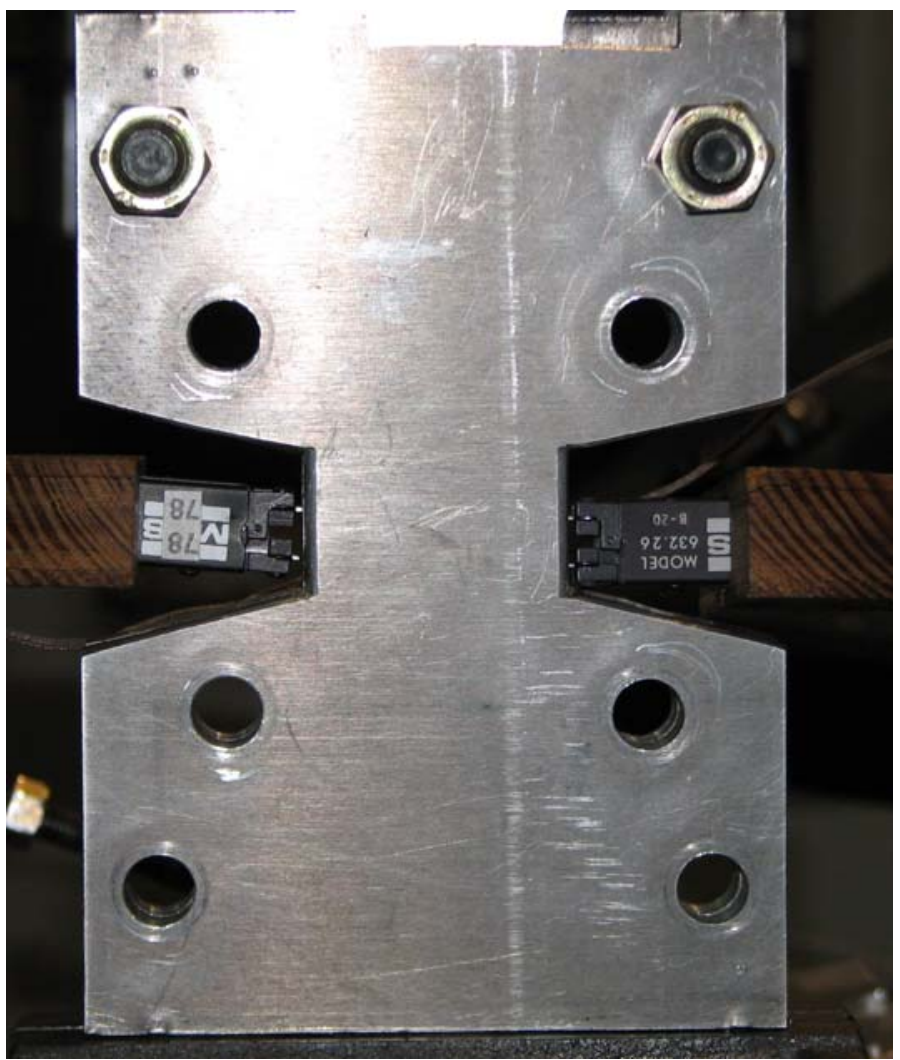

Figure 7 Photograph of guide plates with extensometers.

\section{B. Uniaxial Fatigue Testing}

The uniaxial fatigue tests were conducted using guide plates to restrict out-of-plane displacements due buckling under the compressive loading portion of the fatigue cycles. The guide plates were $3 / 8$ inch thick Aluminum plates that were cut in a dogbone shape that almost completely covered the specimen. A 0.05 inch wide region of the specimen was exposed to allow extensometers to be attached to the edges of the specimen to measure the strain. The guide plates are shown in Figure 7 . The guide plates were held together with 8 bolts and Teflon tape on the guide plates allowed the guide plate to slide freely on the specimen. The distance between the guide plate and the grips of the test machine was set to allow the smallest possible gap at the maximum compressive load.

Specimen thickness below 0.05 inches required additional out-of-plane restraint in the gap between the guide plates and the grips of the test machine. This was accomplished by adding a second set of guide plates on the inside of the first, as shown in Figure 8. The second guide plates were 0.09 inches thick and covered the entire specimen, including the region in the grips. The guide plates were discontinuous to prevent load transfer away from the specimen.

The $\mathrm{R}=-1$ fatigue tests were conducted under displacement control with strain limits. A displacement ramp rate of 0.05 inches/minute was applied. The average strain from the two side extensometers was used to limit the displacement end points. The ramp was reversed when the desired strain value was achieved. A typical normalized stressstrain curve from a uniaxial $\mathrm{R}=-1$ fatigue test is shown in Figure 1. 


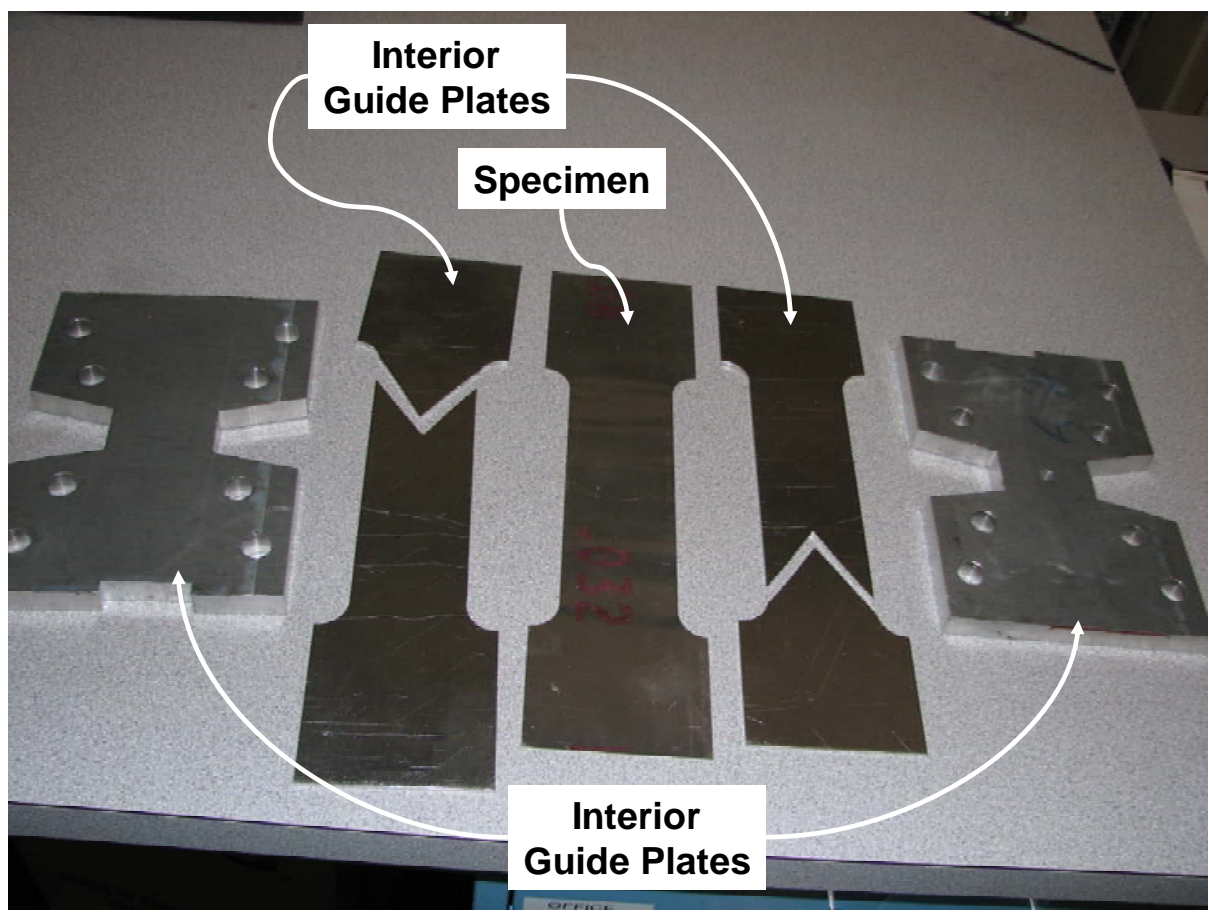

Figure 8 Guide plates for thin specimens.

\section{Bi-axial Testing}

The bi-axial tests were conducted on Aluminum cylinders that were precracked under cyclic pressure loading, wrapped with the composite, fatigue cycled, and broken open to examine the fracture surfaces. The precracking was performed at a stress level identical to that in the uniaxial specimens ( $80 \%$ of yield and a stress ratio of $\mathrm{R}=0.1$ ). Three laser notches were placed in each liner, 120-degrees apart and at different distances from the end of the cylinder, as illustrated in Figure 9. The testing of the wrapped liners has not been accomplished by the time that this paper was written.

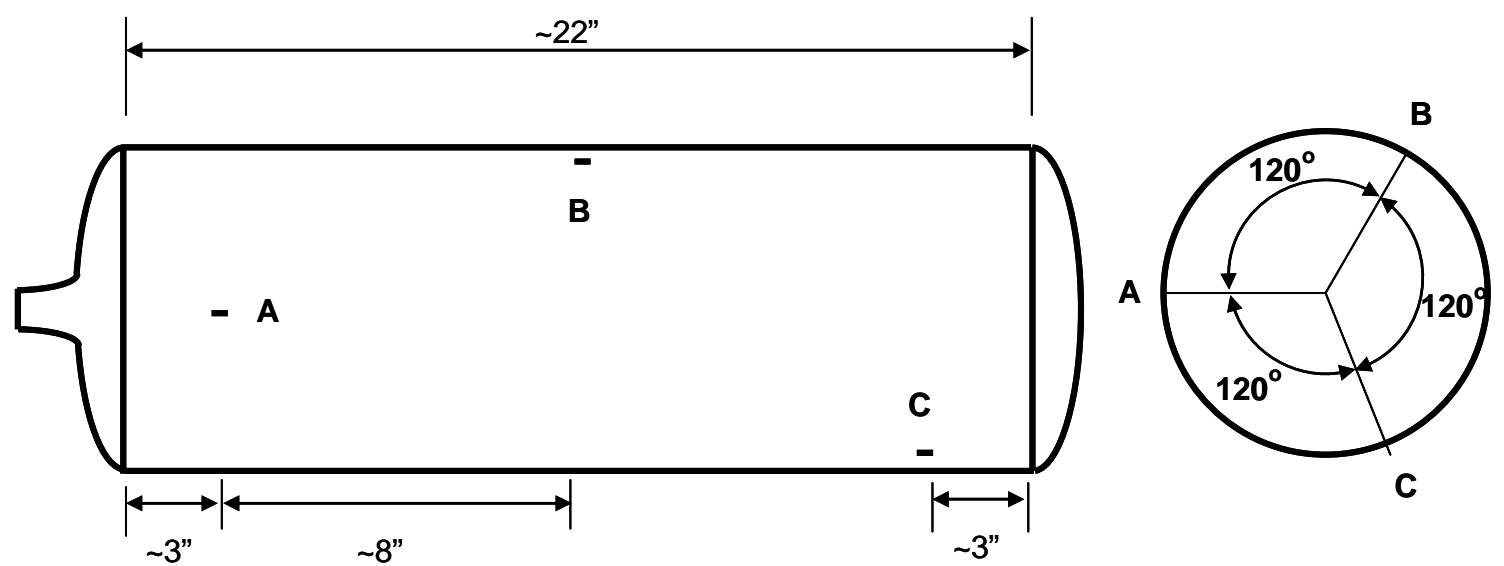

Figure 9 Schematic of the location of the laser notches in the cylinders.

The wrapped liners will be subjected to a cyclic pressure history that will result in a liner strain history, in the hoop direction, similar to that experienced in the uniaxial specimens. The cracks will be cut out of the liners after the pressure cycling and fractured in uniaxial tension. It is anticipated that the fracture surfaces from the wrapped liners will have the same characteristics as the surfaces in the uniaxial tests where the crack fronts at the end of precracking and the end of the fatigue cycling are clearly visible. The crack growth rates for the uniaxial fatigue tests and the bi-axial tests conducted on COPVs will be measured from the distance between the two crack fronts. 
The length and aspect ratios of the uniaxial and bi-axial cracks will be nearly identical and the precracking history will be identical. Any observed differences in the fatigue crack growth rate behavior would likely be due to the different loading conditions (bi-axial versus uniaxial) or the influence of the composite overwrap on the crack growth. An assessment will be made whether the crack growth rates obtained from the uniaxial tests are conservative when compared to the bi-axial tests.

\section{Summary}

This paper presents an experimental procedure for evaluating the validity of using uniaxial tests to provide a conservative bound on the fatigue crack growth rate behavior of small cracks in bi-axially loaded COPV liners. The experimental procedure included the use of a laser notch to quickly generate small surface fatigue cracks with the desired size and aspect ratios. An out-of-plane constraint system was designed to allow fully reversed, fully plastic testing of thin sheet uniaxial coupons. Finally, an experimental procedure was developed to initiate small fatigue cracks in COPVs.

\section{Acknowledgments}

The NESC assessment team created to address this issue consisting of Joseph C. Lewis, Jet Propulsion Laboratory, Lead, David S. Dawicke, Analytical Services and Materials, Inc., NASA/Langley Research Center, Walter Reuter, Swales, NASA/Langley Research Center, Phillip A. Allen, NASA/Marshall Space Flight Center, Robert S. Piascik, NASA/Langley Research Center, Ivatury S. Raju, NASA/Langley Research Center and James B. Chang, Aerospace Corporation.

\section{References}

1. ANSI/AIAA S-081A-2006, “Space Systems-Composite Overwrapped Pressure Vessels (COPVs)” dated July 24, 2006

2. ANSI/AIAA-S081-2000, “Space Systems-Composite Overwrapped Pressure Vessels (COPVs)” dated December 19, 2000

3. Investigation \#06-065-1 (NESC PB-06-55), "Fracture Data for Plastically Responding Liners for Composite Overwrapped Pressure Vessels (COPVs)"

4. King, Jr., Julian P. and Johnson, K. R. “Space Shuttle Orbiter Fracture Control Plan”, Rockwell International Document SD73-SH-0082A, dated September 1974

5. NASGRO Fracture Mechanics and Fatigue Crack Growth Analysis Software, Reference Manual Version 5.2, January 2008, Southwest Research Institute.

6. ASTM Standard E8, 2008, “Test Methods for Tension Testing of Metallic Materials,” ASTM International, West Conshohocken, PA 2008. 